\title{
Characterization of Adsorbents for Thermal Energy Storage in Residential Heating Applications
}

\author{
Kapil Narwal, Roger Kempers, P. G. O'Brien \\ York University, Lassonde School of Engineering \\ 4700 Keele St, Toronto, Canada, M3J 1P3 \\ knarwal@yorku.ca, kempers@yorku.ca,paul.obrien@lassonde.yorku.ca
}

\section{Extended Abstract}

The end-use energy demands in Canada exceed 11,150 PJ and the residential sector accounts for 13\% of this energy demand [1]. Furthermore, $64 \%$ of the total energy consumed in the residential sector is used for space heating and cooling [2]. Natural gas is used to meet 54\% of the residential space heating and cooling [3], and the residential sector is responsible for 85 metric tons of $\mathrm{CO}_{2 \mathrm{e}}$ emissions [4]. Furthermore, Canada is one of the top Green House Gas (GHG) emitters per capita and has committed to reducing its GHG emission by $30 \%$ by 2030 in the Paris Agreement [5]. Canada has taken various measures to meet this commitment including increasing investments in renewable energy [6]. Various renewable energy sources such as hydro, solid biomass, wind, ethanol, landfill gas, biodiesel, solar photovoltaic, solar thermal and tidal are used in Canada to generate a total of 2,119 PJ of energy. However, the contribution from solar thermal energy is only $0.1 \%$ [7].

The average daily solar insolation available from November through March in Toronto, Canada is $7.8 \mathrm{MJ} / \mathrm{m}^{2}$ [8], and the net solar radiance available over an area of $200 \mathrm{~m}^{2}$ during these cold climatic conditions is 1.56 GJ per day [10]. Solar thermal energy, if stored, has the potential to meet the residential heating requirements in Canada. There are various methods to store the thermal energy which include sensible, latent and thermochemical energy storage. Of these, thermochemical thermal energy storage has the highest energy storage density. Thermochemical energy storage may be based on absorption or adsorption processes. The adsorption based thermal energy storage is the focus of this research.

Adsorption is an exothermic thermo-chemical surface process in which adsorbate molecules adhere on the surface of adsorbent particles. The adsorbents, which are nano-porous materials having a very high surface area, can be charged using solar energy. During the charging phase of a solar-driven thermochemical energy storage process adsorbate molecules absorb solar radiation and desorb from the adsorbate surface. The stored energy can be retrieved during the discharging phase by exposing the charged adsorbent particles to the adsorbate molecules. The present research focuses on characterising the adsorbents to meet the requirement of energy storage solutions for residential space heating applications.

Preliminary studies conducted with various adsorbent-adsorbate pairs showed that zeolite 4A-water and zeolite 13Xwater pairs are the most economic (with an actual cost of $285 \mathrm{CAD}$ and $374 \mathrm{CAD}$, respectively) and efficient (maximum heat of adsorption) adsorbent-adsorbate pairs with the minimum mass required, (290 kg and $226 \mathrm{~kg}$, respectively) to meet the spatial heating requirements of a house of four people having an area of $200 \mathrm{~m}^{2}$ [10].

This paper presents the development of an in-house adsorbent apparatus to characterize adsorbent-adsorbate pairs for their thermal energy storage capacities. The adsorbent bed within this characterization apparatus has a volume of $512 \mathrm{~cm}^{3}$ with a $16 \mathrm{~cm}$ length, $8 \mathrm{~cm}$ width and $4 \mathrm{~cm}$ depth. Initial experiments are conducted with zeolite 13X-water adsorbentadsorbate pairs. A $40^{\circ} \mathrm{C}$ temperature rise of the adsorbent was achieved over a duration of 11 hours. This represents a stored energy density of $306.79 \mathrm{~kJ} / \mathrm{m}^{3}$. Future experiments are to be conducted to study the transient responses of Zeolite $13 \mathrm{X}$ and zeolite $4 \mathrm{~A}$ at various relative humidities and carrier fluid flow rates under varied cycle times to find their suitability for thermal energy storage applications. Results from these experiments will be reported and discussed in the context of utilizing solar-thermal energy to provide for the heating requirements of a typical residence located in Southern Ontario. 


\section{References}

[1] Provincial and Territorial Energy Profiles - Canada, Canada Energy Regulator, https://www.cerrec.gc.ca/nrg/ntgrtd/mrkt/nrgsstmprfls/cda-eng.html, Accessed on Feb 13, 2020

[2] Water Heaters, Natural Resources Canada, https://www.nrcan.gc.ca/energy-efficiency/energy-efficiencyproducts/product-information/water-heaters/13735, Accessed on Feb 13, 2020

[3] Cuddihy John, Kennedy Christopher, and Byer Philip, 2005, 'Energy use in Canada: environmental impacts and opportunities in relationship to infrastructure systems', Can. J. Civ. Eng. 32: 1-15 (2005), DOI: 10.1139/L04-100 https://www.nrcresearchpress.com/doi/pdf/10.1139/104-100

[4] Ghajarkhosravi Mahssa, Huang Yirong, Fung Alan S., Kumar Rakesh, and Straka Vera, 2020, 'Energy benchmarking analysis of multi-unit residential buildings (MURBs) in Toronto, Canada', Journal of Building Engineering, Volume 27, January 2020, 100981, https://www.sciencedirect.com/science/article/pii/S2352710219311787

[5] Progress towards Canada's greenhouse gas emissions reduction target, Government of Canada, https://www.canada.ca/en/environment-climate-change/services/environmental-indicators/progress-towards-canadagreenhouse-gas-emissions-reduction-target.html, Accessed on Feb 13, 2020

[6] Canada's actions to reduce emissions, Government of Canada, https://www.canada.ca/en/services/environment/weather/climatechange/climate-plan/reduce-emissions.html, Accessed on Feb 13, 2020

[7] Renewable energy facts, Natural Resources Canada, https://www.nrcan.gc.ca/science-data/data-analysis/energy-dataanalysis/energy-facts/renewable-energy-facts/20069, Accessed on Feb 13, 2020

[8] Natural Resources Canada, Photovoltaic and solar resource maps photovoltaic potential and insolation dataset. http://www.nrcan.gc.ca/18366

[9] Narwal K., 2018, 'Adsorbent-Adsorbate Pairs for Solar Thermal Energy Storage in Residential Heating Applications: A Comparative Study', Proceedings of The Canadian Society for Mechanical Engineering International Congress 2018, CSME International Congress 2018, DOI: 10.25071/10315/35360 